\title{
IMPORT COMPETITION AND EMPLOYMENT IN JAPAN: PLANT STARTUP, SHUTDOWN AND PRODUCT CHANGES
}

(This version is before the referee review process.)

\author{
By EIICHI TOMIURA
}

Research Institute for Economics and Business Administration, Kobe University, Rokko-dai, Nada, Kobe City, 657-8501, JAPAN

March 16, 2001

TEL: +81-(0)78-803-7008

FAX: +81-(0)78-861-6434

e-mail: tomiura@rieb.kobe-u.ac.jp 


\section{IMPORT COMPETITION AND EMPLOYMENT IN JAPAN: PLANT STARTUP, SHUTDOWN AND PRODUCT CHANGES}

This paper examines the relationship between import competition and employment during and after the Bubble boom in Japan. Gross job flow data of 334 manufacturing industries are combined with import data at the four-digit level. The estimates demonstrate that various modes of employment adjustment respond differently to import price changes as follows: Job creation/destruction associated with plant startups/shutdowns was significantly sensitive to import competition. Among continuing plants, job flows, especially job creation during the Bubble boom, at plants changing their product-mix were also responsive, but those at plants maintaining operation within the same industry were not.

JEL Classification Numbers: F14, F41, J23, J63, E24.

\section{Introduction}

The unemployment has been one of the most serious economic issues in Japan since the burst of real estate and stock bubble. Few previous studies, however, have explored the impact of import competition on Japanese employment around this historic change. This paper is intended to be an early contribution toward investigating whether and how import competition affected employment in Japan during and after the Bubble boom.

The following two features differentiate this paper from previous work: First, this paper is the first attempt, as far as the author knows, to evaluate the effect of imports on Japanese employment in terms of job creation and job destruction in disaggregated industries. ${ }^{1}$ The gross job flow data are combined with the import data concorded to the

\footnotetext{
${ }^{1}$ Hampered mainly by the lack of data concordance, analyses of Japanese employment and trade have previously been limited to net employment changes at broadly defined two-digit sectors.
} 
domestic industry classification at the four-digit level. The gross job flow data are derived from Morikawa and Tachibanaki (1999), which were calculated from plant-level data of Census of Manufacturers (Kogyo Tokei, in Japanese). The import data are drawn from Tomiura and Uchida (2001), which is the most detailed, publicly available concordance to date. Such a combined data set has been unavailable without these recently released results of previous work. Since inter-industry variability is substantial, we will expect relatively precise estimates of employment sensitivity by controlling for industry-specific factors at the four-digit level.

Second, by exploiting the detailed information from Census of Manufacturers, this paper compares employment responsiveness not only of newly opened plants, closed plants, plants surviving in the same industry, but also of plants entering from or exiting to other industries by altering their output. Since such product-mix changes at existing plants play a major role in Japanese employment adjustment, and since costs incurred by a producer generally tend to vary across these modes of plant status transfers, this categorization will uncover a previously neglected important aspect of employment changes. As far as the author knows, this paper is the first experiment to distinguish different employment responses to imports among various modes of entry/exit, in the case not only of Japan but also of other countries. ${ }^{2}$

To preview the results, this paper finds that the impact of import competition on Japanese employment during the period around 1990 was significant but small. In this regard, this paper confirms most of the previous studies of Japanese employment sensitivity (e.g. Burgess and Knetter (1998)), but our disaggregation of plant types

\footnotetext{
2 Some previous studies have conducted various disaggregation of entry types, but none of them address international competition. For example, Dunne, Roberts and Samuelason (1988) distinguish
} 
reveals previously unnoticed regularities as follows: Although their effect on total employment changes was weak due to their limited share, significantly influenced by import price changes were job flows by plant startups and shutdowns. The low sensitivity of total employment to imports is mainly driven by the insensitivity of employment at plants remaining in the same industry. Even among incumbents, jobs flows, especially job creation during the Bubble boom, at plants transferring from/to other industries were responsive to import competition. As this paper discovers that import competition of comparable intensity is likely to affect various types of employment adjustment in considerably different ways, implications of the heterogeneous impact of import competition will also be discussed.

The remainder of this paper is organized as follows. Section 2 describes the data. Section 3 formalizes a simple theoretical model. Section 4 presents empirical results. Section 5 concludes.

\section{Description of data}

Before discussing regression results, brief overview of summary statistics will be informative. Table 1 compares the basic statistics of employment and import in Japan during and after the Bubble boom. The employment expanded and import prices rose during the yen-depreciating Bubble boom period (1988-90, Period I), while the employment declined and import prices fell after the burst of the Bubble during the yen appreciation (1990-93, Period II).

The richer information, however, can be drawn from Table 1 because the data set used in this paper disaggregates employment changes in two dimensions. First, 
employment changes are recorded in every four-digit industry. Among 334 industries in our sample, the variation is substantial. ${ }^{3}$ For example, in Period I, employment increased by nearly seven percent in the industry with net employment change one standard deviation above mean, while employment in some industries actually declined during the same boom years.

Second, the data set also disaggregates net employment changes into gross job creation (GJC) and gross job destruction $(G J D) .{ }^{4}$ Behind small net changes (NJC), relatively large job creation and job destruction simultaneously took place, implying that sixteen to twenty percent of total jobs are, on average, reallocated (GJR) every year. The figures also indicate that fluctuations in job creation, rather than in job destruction, characterized the Japanese employment change during these years. ${ }^{5}$

Third, the data set used in this paper further disaggregates GJC into the following three categories: (a) jobs created by newly established plants (GJCE), (b) jobs created by plants surviving in the same industry (GJCS), and (c) jobs created by plants

${ }^{3}$ The coverage of industries is roughly as comprehensive as that in Klein, Schuh, Treist (2000), which contains 442 U.S. four-digit industries.

4 The gross job flow data set from Morikawa and Tachibanaki (1999) covers three census years, 1988, 1990 and 1993. Unless we obtain individual permission from government agency to access to confidential plant-level data, we cannot extend the data to more recent years. After eliminated the industries without one-to-one direct correspondence between domestic industry classification and tariff classification, 334 industries remain as our sample. This paper adopts exactly the same definition of job change rates, including that of denominator, as that by Davis and Haltiwanger (1992).

${ }^{5}$ We cannot, however, generalize this as the Japanese characteristics. First, many previous studies of U.S. data, including Davis and Haltiwanger (1992), unanimously found higher variability of GJD compared with GJC. Second, Tanaka (2000) reports that GJC variability is not always larger than GJD variability in Japan during 1978-98. Although it has an advantage in its long time horizon, the job flow data calculated by Tanaka (2000) is not suited for our purpose because it does not contain 
transferred from other industries (GJCT), since changing product-mix must be an equally plausible tool for a plant to adapt to changing conditions. ${ }^{6} G J D$ is similarly disaggregated by the following plant types: plants exiting by closedown (GJDE), surviving plants which maintain operation in the same industry (GJDS), and plants which transfer to other industries through altering their product-mix (GJDT). ${ }^{7}$ The figures in this table indicate that job creation/destruction in Japan is largely through product-mix changes within existing plants rather than entry/exit of plants. ${ }^{8}$

\section{A theoretical framework}

This section sets out a simple theoretical framework on which the empirical analysis of this paper is based. ${ }^{9}$ First, consider the supply-side of the industry $\mathrm{i}(\mathrm{i}=1,2, \ldots, \mathrm{N})$ at time $t(t=1,2, \ldots, T)$ by the following standard cost function:

detailed disaggregation of industries and entry/exit types.

${ }^{6}$ Although Japan's gross job flows can be calculated from other statistics, such as Genda (1998) and Higuchi and Shimpo (1998), Census of Manufacturers data is better suited for our purpose because it contains not only entry/exit type disaggregation but also non-labor variables such as output shipment and materials inputs in nearly all plants in virtually all tradable industries.

${ }^{7}$ We must note, however, that GJCE and GJDE may not correctly represent the true entry/exit because data of individual plants with no more than three employees are no longer maintained even in the original data files of the government. The impact of this threshold problem, however, is not substantial since employment share of small plants is limited.

8 Davis and Haltiwanger (1992) calculate that between-sector shifts account for very small share of job reallocation in the U.S. Haltiwanger and Schuh (1999) report, also from U.S. data, that continuing plants with mild rates of expansion/contraction occupy notably larger share in between-industry job flows compared with in total job flows.

${ }^{9}$ To facilitate comparison with U.S. results, the deviation of this model follows that of Klein, Schuh and Triest (2000). 


$$
Q_{11}=A\left(\frac{p_{i n}}{e_{i 1} p_{i i}}\right)^{-0} y_{i}^{i}
$$

,where w, c, and Q denote wage, non-labor input costs, and output quantity, respectively. Other factors shifting costs are expressed by $\phi$. Naturally, $0<\gamma_{1}+1<1,0<\gamma_{2}<1$. By Shephard's lemma, the labor demand is derived as following:

$$
L_{i t}=\frac{\partial C_{i t}}{\partial w_{i t}}=\phi\left(\gamma_{1}+1\right) w_{i t}^{\gamma_{1}} C_{i t}^{\gamma_{2}} Q_{i t}
$$

Next, the following standard demand function for the output describes the demand-side of the industry:

$$
Q_{i t}=A\left(\frac{p_{i t}}{e_{i t} p_{i t}^{*}}\right)^{-\theta} y_{t}^{\delta}
$$

,with $p_{i}, p_{i}^{*}, y$ denoting the price of domestic i-th product, the price of imported i-th product, and domestic income, respectively. All the variables, except for the import price $\mathrm{p}^{*}$, are expressed in home-country's currency (yen, in the case of Japan), while $\mathrm{p}^{*}$ is denominated in terms of source-country’s currency (\$, say). The nominal exchange rate (¥/\$, say) is referred to as $e$. The domestic product is assumed to be an imperfect substitute for the imported product. ${ }^{10}$ Other demand shifters are captured by the term A.

\footnotetext{
10 This paper concentrates on the direct competition between final products which are substitutes. On the other hand, import also affects employment through imported inputs. Analyzing these two effects within the same model, however, is empirically difficult because both are often correlated and difficult to distinguish without extensive dependence on input-output tables. Campa and
} 
Both $\theta$ and $\delta$ are assumed to be positive.

By plugging (3) into (2) and by replacing the endogenous own output price, the employment in the industry can be expressed, in the first-differenced logarithm form, as follows:

$$
d \ln L_{i t}=\alpha_{i}+\theta d \ln e_{i t} p_{i t}^{*}+\beta_{1} d \ln y_{t}+\beta_{2} d \ln w_{i t}+\beta_{3} d \ln c_{i t} .
$$

We expect the positive sign for the coefficient on the import price, $\theta$, since the falling import price is likely to intensify competition and leads to lower employment in domestic industries. Obtaining estimates of $\theta$ with employment changes measured in gross terms is the main target of this paper. ${ }^{11}$

\section{Empirical results}

\subsection{Regressions of job creation and job destruction}

The specification derived in the previous section is adapted to the following empirical counterpart, taking account of the focus of this paper and the availability of data:

Goldberg (1998) formalize a model incorporating both routes, although they estimate only the imported input effect.

${ }^{11}$ Assigning instrumental variables to import price, import share and wage could be a better estimation strategy because they are supposed to be determined simultaneously with employment. Assuming exogeneity for these variables is, however, less serious in the case of disaggregated industries such as our four-digit 334 industries. Besides, finding appropriate instruments turns out to be difficult in reality. For example, we cannot have lagged imports because concorded Japan's import data are not available before 1988 due to the drastic tariff classification reshuffle. As far as the author knows, no researchers have ever used industry-specific instrumental variables both to 


$$
\begin{aligned}
& \quad N J C_{i t} \\
& \begin{array}{l}
=\alpha_{i}+\theta_{0} d \ln P_{i t}^{m}+\theta_{1} M S_{i t} d \ln P_{i t}^{m} \\
\quad+\beta_{1} d \ln G D P_{t}+\beta_{2} d \ln E R N_{i t}+\beta_{3} d \ln M T L_{i t}+\beta_{4} d \ln P R D_{i t}+\varepsilon_{i t}
\end{array}
\end{aligned}
$$

,where $P^{m}, M S, G D P, E R N, M T L, P R D$ denote import price (denominated in yen), import share, real GDP, average earnings, materials price, and productivity, respectively. The dependent variable NJC corresponds to the net employment change rate. In the following regression exercises, we will successively replace the left-hand side with GJC, GJD, GJR, GJCE, GJCS, GJCT, GJDE, GJDS and GJDT. The error term $\varepsilon$ is assumed to satisfy usual properties.

The interactive term of import price with the import share MS is included because the sensitivity of employment to imports is likely to vary positively with the industry's exposure to imports. This specification enables us to calculate the industry-specific employment elasticity of the i-th industry $\theta_{i}$ by $\theta_{i}=\theta_{0}+\theta_{1} M S_{i}$.

This paper uses, as the import price data, actual transaction prices of importers derived from WPI statistics. ${ }^{12}$ The import share, MS, of every four-digit industry is calculated based on the data concordance by Tomiura and Uchida (2001). ${ }^{13}$ All other

wage and to import price in analyzing gross job flows.

12 The concordance table is available upon request. Thus drawn import prices are deflated by general WPI index.

${ }^{13}$ The concorded import data by Tomiura and Uchida (2001) is downloadable at the web site. We also calculated the import share in terms of deflated real values, but the ratio barely differs.

Although it will complete the analysis of international competition, we leave the study of export to future work since we believe import effect can be examined separately from export effect, as in Revenga (1992). Besides, no data concordance for Japan's exports is currently available at the comparably disaggregated level. 
data are consistently drawn from Census of Manufacturers. ${ }^{14}$ All variables, except for $G D P$, are industry-specific.

The regression results are reported in Table $2 .{ }^{15}$ The estimates of our concern, i.e. the import price elasticity of job creation/destruction, are precisely estimated with the correct sign. ${ }^{16}$ Table 2 shows that intensified import competition depresses more severely job creation, rather than accelerates job destruction, in this case. This finding of significant responsiveness of GJC, not of GJD, to import price changes, however, might directly reflect higher variability of GJC compared with that of GJD in Japan during this sample period. ${ }^{17}$ This issue will be discussed in the next section.

\footnotetext{
14 The average earnings are defined as the total wage payment divided by the number of employees and deflated by the CPI general index. The material and energy expense is also derived from Census of Manufacturers. The productivity is defined as the shipment value divided by the number of employees and deflated by the domestic WPI of most closely corresponding category. Although it is due to the data limitation in Census of Manufacturers, the choice of employee number, not the total man-hours of work, does not seem to affect the conclusion of this paper since Rebick (1999) found that these two measures result in virtually the same estimates in the trade impact on Japanese employment.

15 The Hausman's specification test significantly rejects the null hypothesis of orthogonality of random effects and regressors for both GJC and GJD at any conventional significance levels. The estimates for coefficients on import price terms are, however, robust even if the random-effect model (RE) is chosen in these cases.

${ }^{16}$ The signs of estimated coefficients on other variables need some discussions. First, GDP is positively correlated with both GJC and GJD. This implies that the Bubble boom activated job reallocations while the burst of the bubble turned reallocation to chill both through job creation and destruction. Second, we found that average earnings are positively/negatively related with job creation/destruction. Higuchi and Shimpo (1998) also found higher GJC in high-earning industries in Japan. This finding may be plausible if we interpret wage as a proxy for quality of human capital. Third, we succeed in finding the correct sign for the non-labor cost. Finally, the productivity growth can have ambiguous sign since rising productivity reduces labor demand but at the same time plants with rising productivity tend to expand their employee size.

${ }^{17}$ Both Klein, Schuh, and Triest (2000) and Gourinchas (1998) found that job destruction is
} 
Evaluated at the average import penetration ratio, one-percent fall of import price is associated with GJC decrease of nearly 0.04 percent and GJD increase of insignificant 0.01 percent, ending up with NJC decrease of around 0.05 percent and GJR decrease of around 0.03 percent. $^{18}$ The decline of GJC due to the import price cut of comparable magnitude is at most one-tenth percent even in industries with the import share one standard deviation above mean. Thus, consistent with existing evidence, the magnitude of Japan's employment sensitivity to import price changes is relatively small. $^{19}$

\subsection{Regressions with disaggregation of entry/exit modes}

Next, Table 3 presents the regression results of the same specification (5), now with detailed categorization of job creation and destruction types. ${ }^{20}$ Since significant responsiveness of job creation found in the previous section is a composite of responses of different job creation types, this paper disentangles GJC into those by newly opened plants, by plants continuing production of the same product, and those by plants entering from other industries through altering the mix of outputs they produce.

significantly responsive to exchange rate changes in the U.S., although Gourinchas (1999) reports that job creation is sensitive in France

${ }^{18}$ Interpreting the estimates in the regression of NJC and those of GJR are obvious since they are, by definition, the straightforward combinations of GJC coefficients and GJD coefficients.

${ }^{19}$ Klein, Schuh, and Triest (2000) estimate, by a similar specification at comparable four-digit level, the U.S. GJD elasticity to be around 0.4. Revenga (1992) reports U.S. elasticity around 0.1-0.4 from net employment changes in four-digit industries. Rebick (1999) finds that impact of import on Japan’s employment is insignificant in his demand decomposition. Burgess and Knetter (1998) conclude that Japan's net employment change is less responsive in cross-country comparison. 20 The estimates from either the fixed-effect (FE) model or the random-effect (RE) model are reported based on the specification test results at the 5\% significance level, although the estimates 
The estimates in Table 3 demonstrate that significant sensitivity of total job creation (GJC) is overwhelmingly attributed to strong sensitivity of job creation by de novo entrants (GJCE). The import price term interacted with import share is clearly significant in the GJCE regression, while neither GJCS nor GJCT discernibly varies with import price changes.

Table 4 reports comparable results for various job destruction types. The import price, not interacted with import share, is found to be significant in the regression of job destruction associated with closedown exits (GJDE). The elasticity of GJDE (0.04) is rather higher than that of GJCE and is in a comparable range with that of GJC in Table 2, evaluated at the mean import share. Therefore, we should not interpret Table 2 as meaning that job creation, not job destruction, is more responsive to import competition in Japan. On the other hand, while GJDS has no systematic relation with import price changes, import price interacted with import share is significant in the GJDT regression.

These estimates reveal that import competition affects employment at various plants in markedly different ways. The employment adjustment associated with plant startups/shutdowns (GJCE/GJDE) is significantly sensitive to import price changes, but that by plants maintaining operation within the same industry (GJCS/GJDS) is not. ${ }^{21}$ The responsiveess of employment to import price changes is not universally low in all Japanese plants ${ }^{22}$, but the sensitivity of total employment is low because insignificant

for import price coefficients are robust.

${ }^{21}$ For plants changing their products, we will discuss in the next section why the estimates here indicate different significance results for GJCT and GJDT.

22 Since no research has yet studied U.S. data with such disaggregated modes of entry/exit, however, interpreting Japan's elasticity with international comparison should be left for future work. As related work, Boeri and Cramer (1992) find that job flows by entrants are much strongly correlated with trend employment growth, although incumbents occupy larger share in annual job flows in 
response of employment at continuing plants overwhelms the significant sensitivity of job flows through plant openings and closedowns. ${ }^{23}$

Although we have discovered that impact of import competition on Japan’s job creation and job destruction is, on average, quantitatively small, our finding of heterogeneous employment responses contains qualitatively important implications as follows: First, entering and exiting plants tend to be small in size. ${ }^{24}$ This means that intensified import competition is likely to induce closures and to restrain possible entry of small-sized plants, while employment in large-sized plants is largely intact. Second, entrants are likely to be armed with newer technologies, while technologies adopted by closedown plants are often outmoded. ${ }^{25}$ Then, intensified import competition tends to accelerate the "cleansing" of obsolete technologies while at the same time it tends to retard the adoption of state-of-the-art ones. Thus, disaggregating job creation and destruction into various types will shed lights on possible linkages of the import competition with other issues, such as industrial organization and technology choice. ${ }^{26}$

\subsection{Alternative specification}

Germany. Davis and Haltiwanger (1992) discover that job reallocation among older, larger plants, which occupies large share, exhibits pronounced variability over cycles in the U.S.

${ }^{23}$ The contribution of continuing plants is strong because openings/closures of plants occupy small share in total job flows and GJDT in this case declined during the same Period II years when NJC declined.

${ }^{24}$ For example, Dunne, Roberts, and Samuelson (1988) reported that entrants tend to be smaller than existing firms. Due to the lack of plant-specific data, our finding of heterogeneous responses might partly reflect difference in plant size.

${ }^{25}$ For example, Doms, Dunne, and Roberts (1995) found that plants employing advanced technology are less likely to fail.

${ }^{26}$ The access to confidential plant-level data of Census of Manufacturers will, in the future 
Next, to check the robustness of the results, this paper also estimate the following specification which includes the period dummy variable interacted with import price terms:

$$
\begin{aligned}
& \operatorname{GJCE}_{i t} \\
& \begin{array}{l}
=\alpha_{i}+\left(\theta_{0}+\eta_{0} D U M_{t}\right) d \ln P_{i t}^{m}+\left(\theta_{1}+\eta_{1} D U M_{t}\right) M S_{i t} d \ln P_{i t}^{m} \\
\quad+\beta_{1} d \ln G D P_{t}+\beta_{2} d \ln E R N_{i t}+\beta_{3} d \ln M T L_{i t}+\beta_{4} d \ln P R D_{i t}+\varepsilon_{i t}
\end{array}
\end{aligned}
$$

, where we define DUM to take the value one for Period I and zero for Period II. ${ }^{27}$ The dependent variable is successively replaced with other modes of job creation/destruction.

Table 5 and 6 report the regressions results of the specification (6). ${ }^{28}$ The results shown in both tables clearly confirm the robustness of previous results in all types of job creation and destruction, except for job created by plants transferred from other industries, GJCT, since DUM is clearly significant only in this case. The inflated job creation in Period I through product-mix changes by existing plants might sound consistent with episodes of active diversification frequently observed during the Bubble boom. ${ }^{29}$ In this sense, we cannot neglect the role of high import prices in disturbing job independent work, enable us to analyze the impact of imports on distribution of plant size.

27 Gourinchas (1998) and Klein, Schuh and Triest (2000) report the asymmetry in the U.S. case, as GJD responds more significantly, compared with GJC, to dollar appreciation, not depreciation.

${ }^{28}$ To check the robustness of results, this paper also examines whether the employment response to imports is affected by omitting some of the explanatory variables from (5). $E R N$ is omitted to check the endogeneity of wage. Other variables are omitted because they could be measured with errors. These experiments confirm that estimated coefficients on import price terms and the main conclusion of this paper are robust irrespective of other control variables.

${ }^{29}$ We might interpret the estimates as follows: The depreciated yen accelerates product-mix 
flows during the Bubble boom.

The interactive term $D U M^{*} M S^{*} d \ln P^{m}$ is, though weakly, significant also in the GJDT regression. Besides, Table 4 has confirmed the clear significance of import price interacted with import share for GJDT. As long as we cannot figure out why the asymmetric response is significant only in transferred plants, we should not decisively argue, but these observations suggest us to summarize our findings of heterogeneous responses in the following way: significantly responsive to import price changes were job flows by plants experiencing inter-industry shifts (GJCT/GJDT and GJCE/GJDE), not by plants remaining within the same industry (GJCS/GJDS). Consequently, we could interpret the results of this paper as consistent with the view that import competition, as a part of international trade, is mainly related to adjustment between industries, rather than within industry.

\section{Concluding remarks}

This paper has examined how the import competition affected Japanese employment during and after the Bubble boom, by combining recently available data sets. The investigation of this period is worthwhile on its own right because analyses of this historic change are undoubtedly required, for example, to help understand the current unemployment problem. The estimates have confirmed that the impact of import competition on Japanese employment during that period was significant but small. This

changes of existing plants toward import-competing industries. On the other hand, the Bubble boom could have inflated demand for imported luxury goods. In addition, firms could afford such plant transformations probably due to sufficiently rich cash flows amid the real estate and stock bubble. Actually, industries with GJCT and import share both high during that period include luxury goods, such as fur, jewels, precious metals, handbags, scarves and ties. The list of those industries is 
paper has also found marked heterogeneity in the response to import price changes among various modes of job creation/destruction.

Tasks left for future studies include the comparison with other cases and the regressions controlling for plant-specific factors. For the former, international comparison will be informative. For the latter, authorized access to confidential plant-level data files of the government will be required.

\section{Acknowledgment}

Masayuki Morikawa provided me with the gross job flow data in electronic form. Yukio Uchida performed excellent research assistance in tabulating data. Kenji Tanaka kindly responded my inquiry about his data set. All remaining errors are mine alone.

available upon request. 


\section{REFERENCES}

Boeri, T. and U. Cramer (1992) "Employment Growth, Incumbents and Entrants:

Evidence from Germany”, International Journal of Industrial Organization Vol. 10, pp.545-565.

Burgess, S. and M. Knetter (1998) “An International Comparison of Employment Adjustment to Exchange Rate Fluctuations”, Review of International Economics Vol. 6, No. 1, pp. 151-163

Campa, J. and L. Goldberg (1998) “Employment versus Wage Adjustment and the U.S.

Dollar”, NBER Working Paper No. 6749.

Davis, S., and J. Haltiwanger (1992) “Gross Job Creation, Gross Job Destruction, and

Employment Reallocation”, Quarterly Journal of Economics Vol. 107, No.3, pp.819-863.

Doms, M., T. Dunne, and M. Roberts (1995) “The Role of Technology Use in the Survival and Growth of Manufacturing Plants”, International Journal of Industrial Organization Vol. 13, pp. 523-542.

Dunne, T., M. Roberts, and L. Samuelson (1988) "Patterns of Firm Entry and Exit in U.S. Manufacturing Industries”, RAND Journal of Economics Vol. 19, No.4, pp.495-515.

Genda, Y. (1998) “Job Creation and Destruction in Japan, 1991-1995”, Journal of the Japanese and International Economies Vol. 12, pp. 1-23

Gourinchas, P. (1998) “Exchange Rate and Jobs: What do We Learn from Job Flows?” in B. Bernanke and J. Rotemberg, eds., NBER Macroeconomics Annual 1998 Cambridge: MIT Press, pp. 153-208.

Gourinchas, P. (1999) “Exchange Rates do Matter: French Job Reallocation and Exchange Rate Turbulence, 1984-1992”, European Economic Review Vol. 43, pp. 1279-1316.

Haltiwanger, J., and S. Schuh (1999) “Gross Job Flows Between Plants and Industries”, New England Economic Review, Federal Reserve Bank of Boston, March/April, pp.52-64.

Higuchi, Y., and K. Shimpo (1998) “Keiki hendo ka ni okeru Wagakuni no Koyou soushutsu to Koyou antei (The Changes of Japanese Job Creation and Job Destruction on Business Cycles)”, Mita Business Review Vol. 41, No. 4, pp.69-101.

Klein, M., S. Schuh and R. K. Triest (2000) “Job Creation, Job Destruction and the Real 
Exchange Rate”, NBER Working Paper No.7466.

Morikawa, M. and T. Tachibanaki (1999) "Entry, Exit, Job creation, and Job Destruction: An Analysis based on the Micro-data of the Japanese Manufacturing Industry”, Discussion Paper, \#99-DOF-32, MITI Research Institute.

Rebick, M. (1999) “Trade and the Wage Structure in the Presence of Price Differentials in the Product Market: The Japanese Labor Market 1965-1990”, Journal of the Japanese and International Economies Vol.13, pp. 22-43.

Revenga, A. (1992) "Exporting Jobs?: The Impact of Import Competition on

Employment and Wages in U.S. Manufacturing”, Quarterly Journal of Economics Vol. 107, No.1, pp.255-284.

Tanaka, K. (2000) "Job Creation and Job Destruction in Japan, 1978-1998: An Empirical Analysis based on Enterprise Data”, Research Report No. 10, Development Bank of Japan.

Tomiura, E. and Y. Uchida (2001) “The Impact of Import Competition on Gross Job Creation and Destruction: A Study based on Japanese Import-Industry Data Concordance”, Discussion Paper, Research Institute of Economy, Trade and Industry. 
TABLE 1

SUMMARY STATISTICS

\begin{tabular}{|l|c|c|c|c|c|}
\hline & PERIOD & AVERAGE & St. DEV & MAX & MIN \\
\hline NJC & I & 0.45001 & 6.4639 & 37.2575 & -32.8943 \\
& II & -1.5179 & 6.588 & 55.8453 & -47.4018 \\
\hline GJC & I & 10.2563 & 5.2838 & 39.1143 & 0 \\
& II & 7.15169 & 4.7190 & 60.4480 & 0 \\
\hline GJD & I & 9.8063 & 5.4736 & 43.5702 & 1.0275 \\
& II & 8.6696 & 4.7180 & 47.4018 & 0 \\
\hline GJR & I & 20.0626 & 8.6009 & 57.3705 & 2.2569 \\
& II & 15.8213 & 6.7563 & 65.0508 & 2.9768 \\
\hline GJCE & I & 2.5254 & 2.0661 & 13.1375 & 0 \\
& II & 1.9553 & 1.3886 & 6.6525 & 0 \\
\hline GJCS & I & 2.8709 & 1.2949 & 12.9482 & 0 \\
& II & 1.7472 & 0.8717 & 4.6954 & 0 \\
\hline GJCT & I & 4.8601 & 4.4058 & 36.1155 & 0 \\
& II & 3.4492 & 4.3460 & 60.1542 & 0 \\
\hline GJDE & I & 2.6650 & 2.3796 & 25.0996 & 0 \\
& II & 2.6794 & 1.9677 & 13.4347 & 0 \\
\hline GJDS & I & 2.3738 & 1.2402 & 10.7767 & 0 \\
& II & 2.2880 & 1.1501 & 7.3511 & 0 \\
\hline GJDT & I & 4.7674 & 4.8232 & 38.0589 & 0 \\
& II & 3.7022 & 3.4953 & 26.6160 & 0 \\
\hline Import Price & I & 3.3710 & 5.5618 & 17.3031 & -12.4677 \\
Change & II & -5.7918 & 4.1963 & 6.7198 & -21.6806 \\
\hline Import & I & 10.0831 & 15.2479 & 98.3209 & 0.0005 \\
Share(MS) & II & 10.6207 & 15.3415 & 95.8838 & 0.0026 \\
\hline
\end{tabular}

Notes: All figures are unweighted averages of 334 industries and expressed in percentage. All the change rates are annualized. Period I and II correspond to the years 1988-1990 and 1990-1993, respectively. See text for abbreviations. 
TABLE 2

REGRESSION OF NET/GROSS JOB FLOWS

\begin{tabular}{|c|c|c|c|c|}
\hline & GJC & GJD & NJC & GJR \\
\hline Import price & 0.0017 & -0.0496 & 0.0513 & -0.0480 \\
& $(0.0481)$ & $(0.0494)$ & $(0.0827)$ & $(0.0517)$ \\
\hline MS*Import price & 0.3712 & -0.1019 & 0.4731 & 0.2693 \\
& $(0.1470)$ & $(0.1510)$ & $(0.2526)$ & $(0.1582)$ \\
\hline$G D P$ & 0.6519 & 0.5418 & 0.1100 & 1.1937 \\
& $(0.1626)$ & $(0.1670)$ & $(0.2794)$ & $(0.1750)$ \\
\hline$E R N$ & 0.2524 & -0.1783 & 0.4307 & 0.0741 \\
& $(0.0777)$ & $(0.0798)$ & $(0.1334)$ & $(0.0836)$ \\
\hline MTL & 0.1478 & -0.0879 & 0.2357 & 0.059881 \\
& $(0.0520)$ & $(0.0534)$ & $(0.0893)$ & $(0.0559)$ \\
\hline PRD & 0.0645 & 0.0398 & 0.0247 & 0.1042 \\
& $(0.0345)$ & $(0.0355)$ & $(0.0593)$ & $(0.0371)$ \\
\hline STATISTICS & $\chi^{2}=31.898$ & $\chi^{2}=21.989$ & $\chi^{2}=9.3633$ & $\chi^{2}=36.536$ \\
& $R^{2}=0.756(\mathrm{FE})$ & $R^{2}=0.732(\mathrm{FE})$ & $R^{2}=0.546(\mathrm{FE})$ & $R^{2}=0.879(\mathrm{FE})$ \\
\hline
\end{tabular}

Notes: Estimated standard errors are in parentheses. All the explanatory variables, except for MS, are in the first-differenced logarithm form. See text for abbreviations. $\chi^{2}$ is the test statistics for the specification test of orthogonality of the random effects and the regressors. These notes apply to the following tables. The results from the fixed-effect model (FE) are reported in this table. 
TABLE 3

REGRESSION OF JOB CREATION

\begin{tabular}{|c|c|c|c|}
\hline & GJCE & GJCS & GJCT \\
\hline Import price & -0.0131 & 0.0041 & 0.0107 \\
& $(0.0163)$ & $(0.0130)$ & $(0.0437)$ \\
\hline MS* & 0.1622 & 0.0083 & 0.2007 \\
Import price & $(0.0499)$ & $(0.0397)$ & $(0.1336)$ \\
\hline GDP & 0.1954 & 0.3724 & 0.0841 \\
& $(0.0552)$ & $(0.0439)$ & $(0.1478)$ \\
\hline ERN & 0.0077 & -0.0040 & 0.2487 \\
& $(0.0263)$ & $(0.0209)$ & $(0.0706)$ \\
\hline \multicolumn{1}{|c|}{$M T L$} & -0.0393 & 0.0415 & 0.1456 \\
& $(0.0176)$ & $(0.0140)$ & $(0.0473)$ \\
\hline \multicolumn{1}{|c|}{ PRD } & -0.0099 & -0.0237 & 0.0981 \\
& $(0.0117)$ & $(0.0093)$ & $(0.0314)$ \\
\hline STATISTICS & $\chi^{2}=9.540$ & $\chi^{2}=24.732$ & $\chi^{2}=36.405$ \\
& $R^{2}=0.757(\mathrm{FE})$ & $R^{2}=0.682(\mathrm{FE})$ & $R^{2}=0.718(\mathrm{FE})$ \\
\hline
\end{tabular}

TABLE 4

REGRESSION OF JOB DESTRUCTION

\begin{tabular}{|c|c|c|c|}
\hline & GJDE & GJDS & GJDT \\
\hline Import price & -0.0418 & 0.0059 & 0.0038 \\
& $(0.0189)$ & $(0.0101)$ & $(0.0355)$ \\
\hline MS* & 0.0897 & -0.0207 & -0.2771 \\
Import price & $(0.0579)$ & $(0.0354)$ & $(0.1243)$ \\
\hline GDP & 0.0939 & 0.0157 & 0.4051 \\
& $(0.0640)$ & $(0.0375)$ & $(0.1316)$ \\
\hline ERN & -0.0351 & 0.0355 & -0.1538 \\
& $(0.0306)$ & $(0.0181)$ & $(0.0637)$ \\
\hline \multirow{2}{*}{ MTL } & 0.0854 & -0.0411 & -0.1153 \\
& $(0.0205)$ & $(0.0122)$ & $(0.0427)$ \\
\hline \multicolumn{1}{|c|}{ PRD } & -0.0087 & 0.0002 & 0.0459 \\
& $(0.0136)$ & $(0.0078)$ & $(0.0274)$ \\
\hline STATISTICS & $\chi^{2}=70.725$ & $\chi^{2}=4.792(\mathrm{RE})$ & $\chi^{2}=5.761(\mathrm{RE})$ \\
& $R^{2}=0.782(\mathrm{FE})$ & & \\
\hline
\end{tabular}


TABLE 5

REGRESSION OF JOB CREATION WITH PERIOD DUMMY

\begin{tabular}{|l|c|c|c|}
\hline & GJCE & GJCS & GJCT \\
\hline Import price & -0.0370 & -0.0014 & 0.0974 \\
& $(0.0267)$ & $(0.0212)$ & $(0.0702)$ \\
\hline DUM $^{*}$ & 0.0401 & 0.0104 & -0.1788 \\
Import price & $(0.0336)$ & $(0.0268)$ & $(0.0884)$ \\
\hline MS* & 0.2354 & 0.0403 & -0.5194 \\
Import price & $(0.0899)$ & $(0.0716)$ & $(0.2364)$ \\
\hline DUM*MS* & -0.1607 & -0.0735 & 1.6787 \\
Import price & $(0.1739)$ & $(0.1385)$ & $(0.4573)$ \\
\hline \multicolumn{1}{|c|}{ GDP } & 0.2143 & 0.3737 & 0.1084 \\
& $(0.0612)$ & $(0.0488)$ & $(0.1610)$ \\
\hline \multicolumn{1}{|c|}{ ERN } & 0.0066 & -0.0042 & 0.2510 \\
& $(0.0264)$ & $(0.0211)$ & $(0.0695)$ \\
\hline \multicolumn{1}{|c|}{ MTL } & -0.0376 & 0.0425 & 0.1195 \\
& $(0.0179)$ & $(0.0143)$ & $(0.0471)$ \\
\hline \multicolumn{1}{|c|}{ PRD } & -0.0087 & -0.0229 & 0.0774 \\
& $(0.0120)$ & $(0.0095)$ & $(0.0315)$ \\
\hline STATISTICS & $\chi^{2}=14.914$ & $\chi^{2}=25.811$ & $\chi^{2}=58.007$ \\
& $R^{2}=0.759(\mathrm{FE})$ & $R^{2}=0.682(\mathrm{FE})$ & $R^{2}=0.730(\mathrm{FE})$ \\
\hline
\end{tabular}

Note: The period dummy, DUM, takes one for Period I (1988-90) and zero for Period II (1990-93). 
TABLE 6

REGRESSION OF JOB DESTRUCTION WITH PERIOD DUMMY

\begin{tabular}{|l|c|c|c|}
\hline & GJDE & GJDS & GJDT \\
\hline Import price & -0.0669 & 0.0032 & -0.0271 \\
& $(0.0309)$ & $(0.0166)$ & $(0.0584)$ \\
\hline DUM $^{*}$ & 0.0423 & -0.0006 & 0.0637 \\
Import price & $(0.0390)$ & $(0.0209)$ & $(0.0735)$ \\
\hline MS* $^{*}$ & 0.1687 & -0.0770 & -0.0561 \\
Import price & $(0.1043)$ & $(0.0495)$ & $(0.1741)$ \\
\hline DUM*MS* & -0.1741 & 0.1471 & -0.5446 \\
Import price & $(0.2018)$ & $(0.0849)$ & $(0.2986)$ \\
\hline \multicolumn{1}{|c|}{ GDP } & 0.1133 & 0.0299 & 0.4063 \\
& $(0.0710)$ & $(0.0409)$ & $(0.1434)$ \\
\hline \multicolumn{1}{|c|}{$E R N$} & -0.0362 & 0.0348 & -0.1518 \\
& $(0.0307)$ & $(0.0182)$ & $(0.0637)$ \\
\hline MTL & 0.0872 & -0.0430 & -0.1115 \\
& $(0.0208)$ & $(0.0122)$ & $(0.0429)$ \\
\hline PRD & -0.0073 & -0.0016 & 0.0506 \\
& $(0.0139)$ & $(0.0079)$ & $(0.0276)$ \\
\hline STATISTICS & $\chi^{2}=79.668$ & $\chi^{2}=5.070(\mathrm{RE})$ & $\chi^{2}=7.226(\mathrm{RE})$ \\
& $R^{2}=0.783(\mathrm{FE})$ & & \\
\hline
\end{tabular}

